\title{
Diferenças imagéticas: considerações sobre a técnica e o símbolo no contexto comunicacional'
}

\section{Imagetic differences: thoughts on technique and symbol in the communication context}

Eduardo Portanova Barros², Anelise Angeli De Carli³, Danilo Fantine/ ${ }^{4}$

\footnotetext{
1 Trabalho apresentado no GT Imagem e Imaginários Midiáticos durante o 240. Encontro Nacional dos Programas de PósGraduação em Comunicação (Compós), realizado de 9 a 6 de junho de 2015, em Brasília (DF).

2 Professor-pesquisador PNPD/CAPES junto ao Programa de Pós-Graduação em Ciências Sociais da Unisinos, realizou pesquisa de pós-doutorado na Université Paris V (Sorbonne/França). Jornalista e pesquisador do Grupo de Estudos sobre Comunicação e Imaginário - Imaginalis. E-mail: eduardoportanova@hotmail.com.

3 Mestranda do Programa de Pós-Graduação em Comunicação e Informação da UFRGS (bolsista CAPES) e integrante do Grupo de Estudos sobre Comunicação e Imaginário - Imaginalis. E-mail: anelisedecarli@gmail.com.

4 Mestrando do Programa de Pós-Graduação em Comunicação e Informação da UFRGS (bolsista CAPES) e integrante do Grupo de Estudos sobre Comunicação e Imaginário - Imaginalis. E-mail: danilo.fantinel@gmail.com.
} 


\section{Resumo}

A pesquisa acadêmica que se debruça sobre os processos comunicacionais, muito frequentemente, tem escolhido como objeto de investigação os produtos da cultura visual contemporânea. A fim de contribuir para aproximações concêntricas junto aos estudos da imagem, este artigo pretende retomar posicionamentos teóricos a respeito de duas noções que, neste campo de pesquisa, costumam ser chamadas "imagem técnica" e "imagem simbólica". Recuperando algumas definições dos estudos da imagem e do imaginário, procuramos observar as diferenças entre estas duas ordens de imagens e suas possíveis articulações. Buscamos, ainda, compreender como tais imagens se apresentam e como se dá a relação delas com a socialidade contemporânea, situando-as como motivadoras da pesquisa em comunicação.

\section{Palavras-chave}

Imagem, imaginário, símbolo, técnica. 


\section{Abstract}

The academic research concerning communication processes usually chooses contemporary visual culture products as objects. In order to contribute to a concentric approximation to the Image Study, this article aims to resume theoretical positions regarding the different concepts of "technical image" and "symbolic image". By retrieving both Image and Imaginary Studies definitions, we observe the distinctions between these two image categories and also their eventual connections. On the other hand, we try to understand how these images present themselves and how they relate to the contemporary sociality, facing them as cause to the Communication Research.

\section{Keywords}

Image, imaginary, symbol, technique. 


\section{Primeira aproximação: imagem técnica e técnica da imagem}

Um dos grandes desafios da pesquisa sobre imagem é sua própria definição, tarefa que se mostra ainda mais complexa quando são usualmente tratados como sinônimos conceitos que, no limite, podem ser mesmo incomensuráveis. Nossa preocupação neste artigo é propor um contraponto entre dois amplos conjuntos: as imagens técnicas, materiais, produzidas pelo homem com o auxílio de aparelhos, conforme definições primeiras de Vilém Flusser (2008; 2011), e as imagens simbólicas, imateriais, intrínsecas ao humano por estarem filiadas a certa constante antropológica, de acordo com postulados de Gilbert Durand (1995; 1998).

Assim como o cinema nasceu de forma interdisciplinar por só ter sido inventado após a descoberta (e por causa) da fotografia, no século XIX, a comunicação também se formou (e ainda se forma) a partir de uma série de interfaces ou influências. O perfil mediador da comunicação na sociedade se traduz em complexidade. Ainda na década de 1950, observa-se a predominância de pesquisas funcionalistas na comunicação. Ao longo do tempo, o quadro foi se alterando, abrindo espaço para estudos mais críticos e complexos, entre os quais destacam-se os teóricos da chamada Escola de Frankfurt, a Teoria Geral do Imaginário, a Semiologia e os Estudos Culturais, entre outros. O pensador francês Edgar Morin, da sociologia crítica, por sua vez, fala-nos de um "paradigma da complexidade", que pode ser definido como um conjunto de princípios ligados uns aos outros, cujas características dialogam entre si.

Essa convergência, que não exclui possíveis contradições, é o que Morin irá denominar de dialogia: "[...] comporta a ideia de que os antagonismos podem ser estimuladores e reguladores. Não é uma palavra-chave que faz com que as dificuldades desapareçam como os que usavam o método dialético" (2001, p. 190). Ora, o princípio dialógico, portanto, não termina em uma resolução perfeitamente acabada e sintética. A dialogia observada em uma imagem nos permite respeitar o próprio estatuto do imaginário, que é sua natureza "alógica". Dos 13 mandamentos (ou "princípios de inteligibilidade") da complexidade estabelecidos por Morin, um deles é, justamente, o de valorização do aspecto dialógico na ciência. O princípio dialógico, portanto, reconhece traços singulares, originais e históricos de certos fenômenos em contraposição a uma visão homogeneizante e simplificadora. "A maneira dialógica e por macroconceitos liga de maneira complementar noções eventualmente antagônicas", de acordo com Morin (2001, p. 334).

Ao contrário disso, segundo ele, teríamos as visões tecnicista (operacionalidade e aplicabilidade da teoria de forma mecânica), doutrinária (fechada ao mundo exterior) e degradante (vulgarização como fórmula de 
choque). No capítulo "As questões do epistemólogo", em A epistemologia, Gaston Bachelard (2010) também se dedicou a escrever sobre a relação do homem e da imagem, mas não, essencialmente, técnica, e sua inserção no mundo. Ele propõe a noção (ou conceito) de "filosofia dispersa" ou "pluralismo filosófico" (2010, p. 27), aqui em outro sentido em relação ao de Morin, como vimos antes, a fim de justificar a importância na filosofia das ciências de um pluralismo filosófico. Se esse pluralismo é vantajoso para não cairmos numa leitura simplista de qualquer teoria, é preciso, porém, fazer uma distinção bem clara, a de que imagem técnica não guarda parentesco necessário com imagem simbólica.

Isso significa dizer que a imagem simbólica, conforme Durand (2000), não é apresentável e objetiva, não depende dos sentidos para ser experienciada. Ora, atribuir à imagem técnica um valor de imagem simbólica, no sentido preciso desta de que nos fala Durand, é um equívoco, e veremos por que razão. Vejamos, no próximo exemplo, de que forma uma imagem é considerada técnica. Para isso, falaremos, mesmo que ligeiramente, de teoria do cinema. Um dos autores no campo cinematográfico que se dedicou a refletir sobre as imagens técnicas foi Arlindo Machado. Segundo ele, "imagem técnica seria toda representação plástica enunciada por ou através de algum tipo de dispositivo técnico" (1997, p. 222). Porém, as coisas não são tão simples assim, como o próprio Machado adverte, já que "[...] é impossível pensar a estética independentemente da técnica" (1997, p. 223). Machado recorda que a "imagem técnica" começou a aparecer na Renascença, a partir de uma tendência por parte dos artistas, ainda segundo Machado, em se apoiarem no conhecimento científico como justificativa para sua arte.

Para Machado, tentou-se buscar verossimilhança com a natureza, através da ciência, e assim se alcançar a essência da imagem técnica. Os artefatos para uso nas artes plásticas, hoje, já estão superados pela videoarte, de acordo com o mesmo autor. Rompeu-se, de acordo com ele, com os "[...] cânones pictóricos do Renascimento" (MACHADO, 1997, p. 233). Esta interpretação, como vemos, é um dos lados da moeda. O que o autor faz é considerar a imagem técnica como o recurso disponível para que o ser humano consiga, já que não possui outros meios para isso, "[...] botar para fora as imagens do nosso cinema interior" (MACHADO, 1997, p. 227). A imagem técnica se refere a uma possibilidade icônica e não ao mistério epifânico do imaginário, pois o imaginário é matriz da razão.

Essa cesura insere-se numa ampla trajetória que descreve o estatuto da imagem no Ocidente. De acordo com Régis Debray (1993), vivemos atualmente sob o domínio da videosfera, ou ainda, a era da imagem visualizada. Se, num momento histórico anterior, nomeadamente a partir do advento da imprensa, a representação caracterizava a relação da humanidade com as imagens, hoje a 
experiência da visualização é dominante. Para ele, a cada período, a civilização carrega uma maneira específica de relacionar-se com as mídias, e esta relação é instauradora da compreensão do mundo vigente em determinada época. A imagem, portanto, é um meio de, um acesso para uma experiência no mundo.

O regime do ídolo, no dizer de Debray (1993), em que a imagem era um ser vidente, sobrenatural, caracterizou o primeiro período histórico ocidental catalogado, desde a sistematização da escrita até a maior invenção de Gutenberg. A Igreja medieval deu prosseguimento às premissas da arte greco-romana da imagem fantasmagórica da divindade. Passando da iconologia à autonomia da arte, a imagem é deslocada do altar para o museu, transformando-se de objeto de culto para objeto de contemplação. O progresso da técnica inaugura, então, um terceiro momento de relação com as imagens: a partir da popularização da transmissão televisiva em cores, nos anos 1960, chegamos à atual era do vídeo.

Mas o que fazer perante a imagem na civilização da imagem? Se a imagem é um meio de acessarmos o mundo, significa dizer que ela ajuda a dar sentido ao mundo. Se vivemos e morremos inseridos em fluxo ininterrupto de imagens, a observação desta materialidade volátil de imagens técnicas deve exigir uma fabricação de sentido. Para concretizarem-se em sentido, essas imagens do mundo exigem motivações profundas, simbólicas. A concretude etérea das imagens simbólicas é constitutiva de sonhos, devaneios, do inconsciente, firmando-se como efetiva proposição de sentidos pelos quais o homem busca sua fixação no mundo. É isso que Durand quer dizer quando afirma que "[...] a imaginação simbólica é [...] a negação do nada da morte e do tempo" (DURAND, 1995, p. 97). A imagem (por um pleonasmo escrita como "imagem simbólica") é a resposta criativa do homem, materialização de sua função simbólica, garantia de equilíbrio vital e psicossocial.

Alguns teóricos apontam a inovação tecnológica (explosão da técnica) como causa do afastamento das imagens de seu poder simbólico. Assim como Debray, André Bazin (1983) lembra que a evolução paralela da arte e da civilização destituiu as artes plásticas de suas funções mágicas como a superação da morte e do tempo pela estética. Para ele, as "imagens mecânicas" provocaram um novo movimento, liberando as artes visuais de seu apego à semelhança e se estabelecendo como "[...] descobertas que satisfazem definitivamente, por sua própria essência, a obsessão pelo realismo" (BAZIN, 1983, p. 124). Apesar das habilidades em favor de um realismo, a pintura é permeada por subjetividade. Característica que, para Bazin, muda radicalmente com a fotografia:

Pela primeira vez, entre o objeto inicial e a sua representação nada se interpõe, a não ser um outro objeto. Pela primeira vez, uma imagem do mundo exterior se forma, automaticamente, sem a intervenção 
criadora do homem, segundo um rigoroso determinismo [...]. Todas as artes se fundam sobre a presença do homem; unicamente na fotografia é que fruímos de sua ausência (BAZIN, 1983, p. 125).

A diferença crucial, para Bazin, reside no fato de que o mecanismo fotográfico "subverteu radicalmente" a psicologia da imagem, conferindo, com auxílio da suposta objetividade, um "poder de credibilidade ausente de qualquer obra pictórica" (1983, p. 125). Segundo Bazin (1984, p. 14, tradução nossa), "[...] a imagem fotográfica é o próprio objeto". Subvertendo ou não a psicologia da imagem, como o então crítico de cinema da Cahiers du cinéma expôs, esse viés baziniano nos remete à imagem de caráter técnico.

A fotografia também é escolhida por Flusser (2011) como o episódio que instaurou uma nova ordem de imagens. Para o filósofo tcheco-brasileiro, as imagens técnicas, produzidas por aparelhos operados pelo homem, como a máquina fotográfica, são obsessivas em sua predisposição em representar o mundo. Mas ele ressalta que estas imagens não são nítidas, especulares, nem objetivas em função da ausência da ação do homem. Ao contrário: tais imagens são visões de mundo sobre as quais recaem tanto a intencionalidade de quem as produziu quanto - talvez mais - as impossibilidades de produção ditadas pela técnica.

É sintomática, portanto, a nossa confusão contemporânea entre imagem e visível, dado que nosso espectro de crença na realidade se dá pela materialização (mesmo em plataforma digital) das imagens em formas. Novamente com Debray (1993), o que não está disponível para a experiência da visão (da atestação através dos sentidos), não é digno de crença. As imagens antigas foram distanciadas dos nossos cotidianos urbanos (cemitérios, igrejas, obras de arte) e substituídas por imagens elaboradas por "máquinas de fazer ver", como a fotografia, o cinema, a televisão e o computador. Não seria válido pensarmos, junto com Paul Virilio (2002, p. 30), no sentido de que a visão substancial acabou trocada pela visualização em razão dos costumes? De acordo com o ensaísta francês, a invenção maciça de todo tipo de aparelho óptico pode ter ocasionado a transformação de que ele fala das imagens mentais para a exigência de se re-presentar nas imagens fornecidas pela tecnologia. "No momento em que pretendemos procurar as formas de ver mais e melhor o não-visto do universo, estamos no ponto de perder o frágil poder de imaginar que possuímos" (VIRILIO, 2002, p. 18).

Notadamente, aquelas são as imagens técnicas de Vilém Flusser. Ainda para Flusser (2008), fotografias, filmes, imagens de TV, vídeo e de computadores performam uma verdadeira revolução cultural porque transportam hoje as informações às quais antes tínhamos acesso através de textos lineares. Em termos de suporte (FLUSSER, 2008, p. 19), testemunhamos uma tecnicidade da imagem 
que, cada vez mais, caminha rumo à abstração - e autonomização dos volumes. Se a imagem (visualidade) tradicional operava uma transformação do concreto para o abstrato, a imagem técnica faz o caminho oposto, ao vincular sua abstração de origem aos textos dos aparelhos (2011, p. 23). Sendo o produto indireto de textos científicos, códigos de signos cada vez mais alheios ao nosso entendimento, nos tornamos cada vez mais funcionários - em suas palavras - dos aparelhos, pois não decodificamos seu funcionamento, a ponto de só conseguirmos imaginar imagens que estariam previamente inscritas em sua programação: "[...] o fotógrafo só pode fotografar o fotografável" (FLUSSER, 2011, p. 46).

Flusser ressalta que as imagens técnicas tendem a ser vistas erroneamente como representações objetivas do mundo. Pois se, aparentemente, hoje todos os textos e imagens tradicionais desembocam em imagens técnicas (2011, p. 29), o significado dessas imagens técnicas acaba impresso de forma automática sobre suas superfícies, embotando a leitura mais profunda de sua substância. O caráter pretensamente objetivo das imagens técnicas faz com que seu observador as olhe como se fossem janelas e não imagens, o que leva a crer que "imagem e mundo se encontram no mesmo nível do real" (2011, p. 30). Ou seja, Flusser aponta para a necessidade de decifração por quem deseja captar-lhes, das técnicas, o significado. Esse significado, para os estudos do imaginário, reside sob um manancial simbólico bastante imbricado e, ao mesmo tempo, misteriosamente convidativo.

As imagens, no entanto, mesmo as técnicas, diferentemente dos textos, trabalham com um elemento adicional para além do código, que é a magia. Para Flusser, a escrita linear nada mais fez do que purificar essa imagem primeira, iniciando um processo ao longo do qual conceituação e magicização foram se destruindo e retroalimentando paradoxalmente, a ponto de "(...) as imagens se tornarem cada vez mais conceituais e os textos, cada vez mais imaginativos" (2011, p. 18). No contexto dessa nova configuração social é que, para Flusser, abre-se espaço para a invenção das imagens técnicas, iniciando pela fotografia, ultrapassando a "crise dos textos". A tese flusseriana da autoria é um paradoxo, porque entre o Eu e a máquina existe um entre-dois. Ora, se a máquina já está preestabelecida, de que forma o Eu-autor pode ser, autenticamente, o detentor do gesto criativo?

\section{Segunda aproximação: a técnica como símbolo do presente}

Para além de uma era do vídeo, a característica mais interessante da contemporaneidade para o antropólogo Gilbert Durand, no entanto, é que a "civilização da imagem" é uma ironia - ou um "efeito perverso" (DURAND, 1998, p. 31), inesperado - consequência da histórica construção iconoclasta 
do conhecimento no Ocidente $^{5}$, que tem seu auge na pedagogia positivista. Também situando a fotografia na ponta dessa tendência, recorda uma série de procedimentos técnicos que, pelo menos desde o século XVI, criaram condições para o surgimento da era do vídeo.

Ou seja, "ao mesmo tempo em que ignorava a imagem como produtora de conhecimento, a ciência positiva viabilizava a técnica para o surgimento da civilização da imagem" (BARROS, 2013, p. 5). Para Durand (1998), todo o desenvolvimento de meios de produção e transmissão de imagens visuais é consequência exatamente de um paradigma científico que afastou a imagem de uma categoria epistêmica. O resultado desse processo pode ser uma forma contemporânea de estar no mundo, inundado de imagem mediática, que não dimensiona bastante bem as potencialidades e desvirtudes da imagem.

Conforme Debray (1993), na contemporaneidade, há uma contração entre imagem e referente, e a imagem visualizada torna-se autossuficiente. Talvez o exemplo mais emblemático dos nossos tempos seja a confusão entre arte e publicidade, pois o valor de apreciação está no espetáculo que a marca faz aderir à imagem (DEBRAY, 1993, p. 242). Ainda, o visual aproxima-se do virtual: podemos ver um prédio que ainda não existe; essa entidade faz descolar da imagem sua realidade física (DEBRAY, 1993, p. 277-278). Imagem e realidade estão se tornando, assim, cada vez mais indiscerníveis. Essa confusão entre imagem e meio ou plataforma tem por consequência o apagamento dos invisíveis. Assim, parece que quanto mais dispositivos para ver o homem aciona, mais cego (à imagem) ele se torna.

O custo desses benefícios de operacionalidade, para o exterior, residiria em uma certa cegueira simbólica, no interior. Há já alguns decênios, a extensão dos espaços observáveis parece estar sendo paga com a amputação dos territórios da utopia. Quando o espectro da radiação eletromagnética estava reduzido à luz visível pela retina, o invisível tinha uma realidade infinitamente maior (DEBRAY, 1993, p. 362).

Mesmo admitindo a proximidade desses invisíveis a um sistema de ideogramas, percebe-se, portanto, que a imagem da qual fala Debray é mais do que representação - essa é somente uma de suas possibilidades de encarnação. Ultrapassando a experiência visual, a imagem também pode ser o lugar do

5 Durand (1998) descreveu quatro grandes marcos na história da civilização ocidental que evidenciam um esforço iconoclasta: o método da razão aristotélica (séc. IV a.C.), a proliferação da escolástica medieval nas primeiras universidades (séc. XI a XIII), a aderência nos meios letrados do cartesianismo e do empirismo (séc. XVII) e o método científico (séc. VIII) ainda em vigor. 
imaginável que não é visível. Os territórios de utopia do filósofo francês se aproximam ao simbólico de Durand.

A Teoria Geral do Imaginário fala de outra imagem que não a iconográfica. Segundo Durand (1995, p. 8-10), além do signo e da alegoria, quando nenhuma parte de um significado é apresentável, temos um terceiro grau de imagem disponível à consciência, a imaginação simbólica. É através da noção de arquétipo de Jung que Durand diferencia a imagem que é fruto de representação (alegoria, signo) daquela que é fruto e ao mesmo tempo consequência de uma apresentação (símbolo $)^{6}$. Através da faculdade simbólica, o homem acessa este sistema de virtualidades a que se nomeia arquétipos do inconsciente coletivo. A concretização do simbólico se dá na associação entre arquétipo e uma imagem reconhecível pela consciência humana - que pode ser uma visualidade ou uma narrativa em esquema linguístico qualquer.

Durand acentua o papel mediador do símbolo, avaliando que "[...] através da faculdade simbólica, o homem não pertence só ao mundo superficial da linearidade dos signos, ao mundo da causalidade física, mas também ao mundo da irrupção simbólica, da criação simbólica contínua" (DURAND, 1995, p. 57). A imagem promove o contrário da assujeição, favorece o empoderamento dos sujeitos. No sentido de que a imagem simbólica só funciona através da produção de um imaginário ativo.

Descrevendo as características do mundo contemporâneo, ou da pósmodernidade, Maffesoli (2003, p. 47) dá à imagem o importante papel de substrato epistemológico da constituição do sujeito e da sociedade. Justamente como consequência paradoxal da tradição ocidental iconoclasta, presenciamos um retorno vigoroso da imagem negada e repelida. Para o sociólogo francês, a tecnologia favorece um reencantamento pelo mundo, um verdadeiro renascimento do mundo imaginal (modo de pensar através da imagem) e reposicionamento da imagem como promotora de vínculos sociais ou, em suas palavras, o "estarjunto fundamental"7. Apesar de preocupar-se com a ordem da representação,

6 Percebe-se, portanto, que para a corrente arquetipológica do imaginário ao qual Durand está filiado, o símbolo não é um tipo de signo (como repetido pelos estudos de comunicação afiliados à abordagem pragmatista peirceana), é, antes, seu contrário (1995).

7 É preciso, no entanto, evidenciar as diferenças entre o pensamento de Debray e Maffesoli. Se o filósofo assumia a materialização da imagem em três grandes ciclos (iconosfera, grafosfera e videosfera), Maffesoli fala de uma mesma imagem que retorna na emergência de valores arcaicos no cotidiano contemporâneo: "[...] o social cresce em socialidade integrando, de maneira holística, parâmetros humanos descartados pelo racionalismo moderno" (MAFFESOLI, 2003, p. 48). 
Debrayb anuncia as midiasferas (1993, p. 354) como grandes eras que descrevem a relação da civilização com o real, as ideologias" ${ }^{8}$ Essa visualização, essa "técnica da imagem", pode ser pensada como meios de socialidade maffesoliana. A mediação social, então, promovida pelas imagens, fala de maneiras de relacionarse simbolicamente com os sentidos do mundo.

É do simbólico desta "civilização da imagem" que Durand (1998) questiona a eficácia. As imagens da contemporaneidade, como já dito anteriormente, são resultado inesperado da iconoclastia, inimiga do pensamento imagético e defensora da razão como único meio de acesso à verdade. Nesse sentido, o imaginário cada vez mais é confundido com delírio, sonho ou irracional. Durand descreve os períodos civilizacionais como tópica sociocultural, ou seja, disposição dos elementos num lugar, um topos, que assinala suas relações mútuas. Ele situa o lugar das imagens na socialidade fazendo um paralelo com o diagrama freudiano da psique individual, em que um círculo se divide em consciente e inconsciente (1998, p. 93). Na camada mais profunda estaria submerso o inconsciente coletivo, o "isso" antropológico (id), nascedouro das imagens simbólicas anteriormente referidas, pobres em figuração e fortes em estrutura funcional. Na camada do meio deste diagrama (lugar do ego na psique individual), repousariam as máscaras da identidade, estratificações sociais aos quais aderimos para a inserção nos grupos: classe, sexo, idade etc. Acima (superego), controlando e organizando os códigos socioculturais, estaria a sociedade mesma e seus planos ideológicos vigentes.

No entanto, além de situar "espacialmente" as esferas do simbólico da vida societal, Durand adiciona outra dimensão a este diagrama: o tempo. A esse esquema tripartido (respectivamente constante antropológica, ego sociocultural e sociedade) adiciona-se uma seta que vai de baixo para cima à margem do círculo, e, depois, de cima para baixo, dinamizando o lugar das imagens de acordo com cada época. Ou seja, os conteúdos imaginários simbólicos complexos do id passam pelo escrutínio sociocultural, aparando suas arestas inconformes, alógicas, próprias do arquétipo, até atingirem o topo do diagrama e tornarem-se "ideologia" de determinada época (algo como a textualização das imagens em Flusser).

Movimentos antagônicos se sucedem nesta dinâmica, adequando a polissemia das imagens simbólicas e transformando-as em ideologia, e, posteriormente, fazendo a inadequação da ideologia parecer tão premente a ponto de promover um reafundamento dessas imagens para o id profundo novamente. É este movimento que permite o desenrolar da história.

8 Até mesmo Guy Debord aponta o espetáculo como "instrumento de unificação" (1997, p. 14) de uma sociedade, a própria maneira com a qual se dá a relação social entre as pessoas. Essa relação é mediada pelas imagens. É por este motivo que o pensador francês integra o rol dos pensadores da imagem. A imagem a qual se refere, no entanto, é a imagem da representação, quando a realidade e a imagem se separam provocando um deslocamento, um falseamento, dos sujeitos com os fenômenos do mundo. 


\section{Terceira aproximação: o simbólico como técnica da imagem}

Diferentemente das imagens técnicas e/ou visuais, as imagens simbólicas dispensam decodificação, significação ou qualquer tipo de análise arbitrária que busque explicar as representações de mundo captadas e impressas em suas superfícies. Ao contrário, são próprias a uma leitura multifocal que dê atenção a sua polissemia. Resultado do trajeto antropológico (DURAND, 2012), um tensionamento incessante entre as pulsões do homem e as coerções provenientes do meio social, as imagens simbólicas são pregnantes justamente porque não representam, elas efetivamente são - ou, em outras palavras, elas não significam algo, pois não ligam dois elementos distintos, porém conservam um sentido por serem símbolos hermenêuticos. Esse ser guarda em si uma multiplicidade de sentidos ligados à carga afetiva das imagens simbólicas - afeto entendido aqui na amplitude do termo, indo de ternura à turbulência em uma miríade de relações sensíveis e complementares que se dá entre o sujeito e a imagem.

As imagens simbólicas são produzidas e deformadas pela imaginação criadora (BACHELARD, 1990, p. 7-9) do homem. Vivenciadas pelo sujeito imaginante, afetam e transformam-no em função da harmonização da essência do ser com as intimações do mundo histórico-social, residindo neste ponto uma de suas principais diferenças com relação às imagens técnicas. Paralelamente, problematizam a existência e propõem sentidos que explicam o homem e o fixam no tecido sociocultural - sentidos que, conforme Durand, "[...] não devem ser procurados fora da significação imaginária" (2012, p. 29) e que, de acordo com Norval Baitello Jr., não são construções arbitrárias do espírito, mas "[...] um conjunto de vínculos maiores que levam em conta o homem na sua dimensão histórica, política e social, mas também psicológica e antropológica, ou seja, em sua inteira complexidade" (DURAND, 2014, p. 105) - fruto da experiência, que ultrapassa a lógica analítico-semiótica.

A tese de Baitello é a de que somos devorados por imagens, daí o termo "iconofagia" ao qual ele se reporta. Se for assim, o autor é obrigado a reconhecer, como o faz, de fato, que "[...] as imagens é que nos procuram" (BAITELLO, 2014, p. 68). Aqui somos provocados a insistir na diferença entre imagem técnica e imagem simbólica. Baitello fala, evidentemente, do primeiro tipo de imagem, técnica, que não é o primeiro em termos de anterioridade ontológica. O imaginário é inerente ao homem, mas não o é a técnica imagética criada, artificialmente, para o seu desenvolvimento na cultura. O simbólico não é apenas cultural, a não ser se tomarmos como simbólico a ideia de um "capital" em Bourdieu, que, nem de perto, é o nosso caso. De acordo com Baitello, quando as imagens que temos procedem de outras imagens, estamos no primeiro degrau da iconofagia. Ao consumi-las, 
atingimos o segundo estágio. Em comum, observa-se, segundo ele, a vontade de nos distanciarmos da morte. A imagem, assim, é mais do que imagem.

O que nos revela a "iconofagia" é o fato de que somos produtores e produtos de imagens. Mas é de se notar que as imagens não nos devoram por vontade própria, como se elas fossem uma instância separada do ser. O ser, aqui, nos remeteria ao caráter "alógico" do imaginário.

Se o imaginário produz imagens não é porque, objetivamente, esta imagem é criada ad hoc e sim porque, conforme nos indica a arquetipologia durandiana referida anteriormente, o ser se viu, necessariamente, instaurador desses regimes da imagem ${ }^{9}$. Poderíamos, ainda, sugerir uma ideia no sentido de que a imagem técnica é toda a imagem produzida pela invenção racional do homem, enquanto a imagem simbólica é um espaço-tempo direto da imaginação. Imagem técnica, por exemplo, é toda imagem fotográfica. Imagem simbólica, por sua vez, é uma interioridade caótica, sem qualquer traço de objetividade, mas, de qualquer forma, estruturante.

\section{Quarta aproximação: a que imagem nos reportamos?}

Ao contrário das imagens técnicas, as imagens simbólicas não têm molduras nem passam por enquadramentos, não têm formato físico ou suporte material, são imagens mentais nascidas no corpo humano; porque temos um corpo, um cérebro, uma condição humana; imagens que, assim como arquétipos, símbolos, mitos e metáforas, constituem o imaginário antropológico. Este é "(...) o grande denominador fundamental onde se vêm encontrar todas as criações do pensamento humano" (DURAND, 2012, p. 18), base sobre a qual atuam, conforme Carl Gustav Jung, os arquétipos, estes "[...] esquemas ou potencialidades funcionais" que "[... ] determinam inconscientemente o pensamento" (DURAND, 2012, p. 30).

Conforme Jung, o inconsciente é formado por uma camada superficial, o inconsciente pessoal, que repousa sobre uma camada mais profunda, desvinculada de experiências ou aquisições pessoais, inata, cuja denominação inconsciente coletivo remete à natureza universal, e não estritamente individual, do inconsciente como um todo. Contrariamente à psique pessoal, o inconsciente possui conteúdos e modos de comportamento "(...) idênticos em todos os seres humanos, constituindo um substrato psíquico comum de natureza psíquica suprapessoal que existe em cada indivíduo" (JUNG, 2002, p. 15) - cujos elementos são espelhados pelo imaginário antropológico.

Enquanto os conteúdos do inconsciente pessoal apresentam complexos de tonalidade emocional, os elementos do inconsciente coletivo são chamados

9 Durand (2012), simplificando, caracterizaria como diurno (cortante, virilizado) e noturno (acolhedor, uterino). 
arquétipos, ou tipos primordiais, isto é, "(...) imagens universais que existiram desde os tempos mais remotos" (JUNG, 2002, p. 16), explicitadas como componentes impessoais, socioculturalmente herdadas. São imagens coletivas, "(...) cuja existência étnica há muito é conhecida", ou seja, imagens ancestrais que se propagaram universalmente e "(...) irrompem na existência através de uma função psíquica natural" (JUNG, 1978, p. 13). Formas conhecidas de expressão dos arquétipos são encontradas nos mitos, narrativas explicadoras da conduta humana transmitidas através das gerações. Porém, sua manifestação imediata, como em sonhos e visões, é muito mais individual, incompreensível e ingênua do que nos mitos: "O arquétipo representa essencialmente um conteúdo inconsciente, o qual se modifica através de sua conscientização e percepção, assumindo matizes que variam de acordo com a consciência individual na qual se manifesta" (JUNG, 2002, p. 17).

Nesse ponto, os arquétipos tendem a se transformar em imagens simbólicas, cujos sentidos estão impregnados pela experiência do homem, acarretando assim a multiplicidade semântica própria deste tipo de imagem. Apesar da manifestação dos arquétipos serem diferentes no âmbito pessoal, sua expressão nos mitos também aponta o caráter universal do inconsciente coletivo. Assim é que se explica o fato de que os processos inconscientes dos povos, separados no tempo e no espaço, apresentem uma correspondência impressionante, que se manifesta, entre outras coisas, pela semelhança fartamente confirmada de temas e formas mitológicas autóctones. A semelhança universal dos cérebros determina a possibilidade universal de uma função mental similar. Essa função é a psique coletiva. Na medida em que há diferenciações correspondentes à raça, tribo ou mesmo à família, também há uma psique coletiva que pertence à raça, tribo e família, além de uma psique coletiva universal (JUNG, 1978, p. 22).

Jung estabelece que o inconsciente jamais se encontra em repouso, inativo, pois está sempre produzindo, agrupando e reagrupando seus conteúdos, sendo eles pessoais ou extrapessoais, revelando "uma atividade psíquica alheia à nossa vontade" (JUNG, 1978, p. 7). Porém, não podemos atribuir ao inconsciente uma psicologia consciente. Sua mentalidade é de caráter instintivo, sem funções diferenciadas, e nem pensa segundo os moldes daquilo que entendemos por "pensar". Ele somente cria uma imagem que responde à situação da consciência. Conforme Jung, esta imagem é tão impregnada de ideia como de sentimento e poderá ser tudo, menos o produto de uma reflexão racionalista.

O caráter criador do inconsciente, a presença dos arquétipos no inconsciente coletivo e as narrativas míticas nas quais estas imagens primordiais se articulam ganham expressão nas crenças e culturas de diferentes povos em diferentes épocas, que frequentemente recorrem ao simbolismo para fundamentar o pensamento 
e o conhecimento não formal. Conforme Mircea Eliade (2002), o pensamento simbólico é domínio de todos os seres humanos, precedendo a linguagem e a razão discursiva, chegando a desvendar os mais profundos aspectos da realidade. Na mesma esteira das funções simbólicas de equilíbrio anteriormente descritas por Durand, "[...] as imagens, os símbolos, os mitos não são criações irresponsáveis da psique; eles respondem a uma necessidade e preenchem uma função: revelar as mais secretas modalidades do ser" (DURAND, 2002, p. 9).

Para Eliade, o estudo do símbolo permite-nos conhecer melhor o homem que ainda não se compôs com as condições da história, pois cada ser histórico transporta consigo uma grande parte da humanidade anterior à história. Esta parte a-histórica do ser humano traz uma memória de existência rica e completa. Por isso, Eliade alega que o inconsciente estudado por Jung é habitado por deuses, heróis, fadas e monstros que desempenham as mesmas funções que lhes pertenceram em todas as mitologias: ajudar o homem a libertar-se e a aperfeiçoar-se.

É essa vivacidade das imagens que é observada com propriedade por Bachelard (2001), para quem o real entendimento sobre a (imagem) simbólica depende ou de uma vivência mútua com a mesma, no âmago do ser, ou de uma entrega incondicional a sua transcendência, deixando-se o sujeito afetar ou ser tocado pela imagem - sem a necessidade do domínio da linguagem verbal para sua compreensão.

\section{Considerações finais}

Elaborando uma revisão das mais referenciadas concepções acerca do conceito de imagem no âmbito dos estudos da imagem e do imaginário, encerramos o artigo apontando para as virtudes e dificuldades que o campo da comunicação deve enfrentar a fim de elaborar análises de valor acerca da imagem. Enquanto dividimos pedagogicamente a imagem em duas instâncias lexicais, é preciso lembrar, no entanto, o que explica Teixeira Coelho (1997): "(...) a imagem [simbólica] não pode ser interpretada a partir da consciência ou só do inconsciente, mas apenas a partir da relação recíproca entre um e outro" (1997, p. 208). Uma primeira diferença estaria em termos de acesso: a imagem técnica nos é apresentada conscientemente, estimulando os sentidos, a exemplo de um filme ou fotografia. O símbolo não é redutível ao signo-representação, mas é também parte desta técnica.

Explicamos: muito embora aparentemente a imagem técnica prescinda da imagem simbólica e vice-versa, nossa hipótese apaziguadora é apontar para uma possível mixidez entre técnica e símbolo no contemporâneo - e esta atividade tem como protagonista o processo da comunicação. Apesar dos diversos teóricos 
que apontam as diferenças entre as imagens técnicas e as imagens simbólicas, o pesquisador dedicado ao estudo das imagens - e principalmente aquele que toma os estudos do imaginário como heurística - tende a observar os produtos da cultura como obras que contêm conteúdo simbólico. A leitura procura permitir que o homem pertença não só ao "mundo superficial dos signos", mas, principalmente, "ao mundo da irrupção simbólica" (DURAND, 1995, p. 57).

Que faz o analista das imagens técnicas do contemporâneo (na esteira de Maffesoli, Debray, Flusser e outros) se não descobrir onde reside o encantamento pela produção de visualidades? Os efeitos da era do vídeo na socialidade contemporânea ainda estão por ser contemplados mas, hoje, tem-se por certeza que as comunicações em seus múltiplos dispositivos é que são responsáveis pela re-ritualização dessas figuras. Como vimos, à imagem retorna a condição de símbolo quando ela se impregna de sentido. Seria possível então dizer que a imagem contemporânea, cada vez mais técnica, estaria revelando uma nova faceta, um símbolo, do mundo presente?

Se nos escorre pelas mãos uma definição possível de imagem, possivelmente é porque estejamos vivendo em seus processos. A viscosidade do símbolo, a capacidade de motivar aspectos interiores da nossa existência é, talvez a técnica mesmo da imagem. O símbolo, a capacidade de simbolizar, seria a técnica mesmo da imagem? Quer seja através de dispositivos de fazer ver, de compartilhar informações ou de contar histórias, a imagem transita por diferentes atualizações em seus formatos, muito embora carregue em seu âmago aquilo que não Ihe pode ser tomado: o sentido. Mesmo inconstante em definições, a morada da imagem no eterno entremeio das ortodoxias se mantém - sintoma de que ela está, sobretudo, viva. 


\section{Referências}

BACHELARD, G. A epistemologia. Lisboa: Edições 70, 2010.

BACHELARD, G. A terra e os devaneios da vontade: ensaio sobre a imaginação das forças. São Paulo, Martins Fontes, 2001.

BACHELARD, G. O ar e os sonhos. São Paulo: Martins Fontes, 1990.

BAITELLO JR., N. A era da iconofagia: reflexões sobre imagem, comunicação, mídia e cultura. São Paulo: Paulus, 2014.

BARROS, A. T. M. P. "O imaginário e a hipostasia da comunicação". In: Revista Comunicação, Mídia e Consumo, ESPM, v. 10, n. 29, set.-dez. 2013, p. 13-29.

BAZIN, A. "Ontologia da imagem fotográfica". In: XAVIER, I. (org.). A experiência do cinema: antologia. Rio de Janeiro: Graal, 1983, p. 121-128.

BAZIN, A. What is cinema? v. 1. Los Angeles: University of California Press, 1984.

DEBORD, G. A sociedade do espetáculo. Rio de Janeiro: Contraponto, 1997.

DEBRAY, R. Vida e morte da imagem: uma história do olhar no Ocidente. Petrópolis: Vozes, 1993.

DURAND, G. A imaginação simbólica. Lisboa: Edições 70, 1995.

DURAND, G. As estruturas antropológicas do imaginário: introdução à arquetipologia geral. São Paulo: Martins Fontes, 2012.

DURAND, G. O imaginário: ensaio acerca das ciências e da filosofia da imagem. Rio de Janeiro: Difel, 1998.

ELIADE, M. Imagens e símbolos: ensaio sobre o simbolismo mágico-religioso. São Paulo: Martins Fontes, 2002.

FLUSSER, V. Filosofia da caixa preta: ensaios para uma filosofia da fotografia. São Paulo: Annablume, 2011.

FLUSSER, V. O universo das imagens técnicas: elogio da superficialidade. São Paulo: Annablume, 2008. 
JUNG, C. G. O eu e o inconsciente. Petrópolis: Vozes, 1978.

JUNG, C. G. Os arquétipos e o inconsciente coletivo. Petrópolis: Vozes, 2002.

MACHADO, A. Pré-cinemas \& pós-cinemas. Campinas, SP: Papirus, 1997.

MAFFESOLI, M. O tempo retorna: formas elementares da pós-modernidade. Rio de Janeiro: Forense, 2012.

MAFFESOLI, M. "Mediações simbólicas: a imagem como vínculo social". In: MARTINS, F. M.; SILVA, J. M. (orgs.). Para navegar no século XXI. $3^{a}$ ed. Porto Alegre: Sulina/EdiPUCRS, 2003, p. 37-48.

MORIN, E. Introdução ao pensamento complexo. Lisboa: Instituto Piaget, 1991.

MORIN, E. Ciência com consciência. Rio de Janeiro: Bertrand Brasil, 2001.

TEIXEIRA COELHO, J. Dicionário crítico de política cultural. São Paulo: Iluminuras, 1997.

VIRILIO, P. A máquina de visão. 2a ed. Rio de Janeiro: José Olympio, 2002.

submetido em: 01 set. 2015 | aprovado em: 04 dez. 2015 